\title{
Promises of meat and milk alternatives: an integrative literature review on emergent research themes
}

\author{
Annika Lonkila $^{1}$ (D) $\cdot$ Minna Kaljonen $^{1}$ (D)
}

Accepted: 28 November 2020 / Published online: 30 January 2021

(c) The Author(s) 2021

\begin{abstract}
Increasing concerns for climate change call for radical changes in food systems. There is a need to pay more attention to the entangled changes in technological development, food production, as well as consumption and consumer demand. Consumer and market interest in alternative meat and milk products—such as plant based milk, plant protein products and cultured meat and milk-is increasing. At the same time, statistics do not show a decrease in meat consumption. Yet alternatives have been suggested to have great transitional potential, appealing to different consumer segments, diets, and identities. We review 123 social scientific journal articles on cell-based and plant-based meat and milk alternatives to understand how the positioning of alternatives as both same and different in relation to animal-based products influences their role within the protein transition. We position the existing literature into three themes: (1) promissory narratives and tensions on markets, (2) consumer preferences, attitudes, and behavioral change policies, (3) and the politics and ethics of the alternatives. Based on our analysis of the literature, we suggest that more research is needed to understand the broader ethical impacts of the re-imagination of the food system inherent in meat and milk alternatives. There is also a need to direct more attention to the impacts of meat and milk alternatives to the practices of agricultural practices and food production at the farm-level. A closer examination of these research gaps can contribute to a better understanding of the transformative potential of alternatives on a systemic level.
\end{abstract}

Keywords Alternative protein $\cdot$ Milk alternative $\cdot$ Meat alternative $\cdot$ Protein transition $\cdot$ Sustainable food system $\cdot$ Literature review

\section{Introduction}

Meat and milk alternatives have been proposed as a promising alternative to the many problems caused by the overreliance of contemporary Western diets on animal protein. They are promoted as providing solutions to animal welfare (Schaefer and Savulescu 2014), GHG emissions (Tuomisto and Texeira de Mattos 2011); human health (Bhat et al. 2019), as well as resource efficiency (van der Weele et al. 2019). In recent years, the food industry has taken the lead in developing novel foodstuffs that are positioned as alternatives to meat and milk. Both consumer and market interest in

Annika Lonkila

annika.lonkila@syke.fi

Minna Kaljonen

minna.kaljonen@syke.fi

1 Finnish Environment Institute, Latokartanonkaari 11, Helsinki, Finland these products is increasing. At the same time, these products enter crowded markets and become entangled in contested discourses on sustainable protein transition.

To date, the promises related to meat and milk alternatives have received considerable attention from social scientists. They have been investigated as a dynamic example of market driven transition, where new innovations and incumbent industries aim to provide solutions for more sustainable protein sources (e.g. Mylan et al. 2019; Tziva et al. 2020). An increasing number of researchers have started to talk specifically about protein transition to highlight the necessity to find more sustainable sources of protein that can replace meat and milk in the western diets (de Boer and Aiking 2018; Tziva et al. 2020; van der Weele et al. 2019). Much of the research on protein transition has focused upon technological solutions offered by cell-based meat and milk alternatives (Hocquette 2016; Bhat et al. 2019; Kadim et al. 2015; Sexton et al. 2019). The understanding of the role of other plant-based products in the protein transition has 
remained much more fragmented (see also van der Weele et al. 2019). Further investigation of the variety of product categories (ranging from in vitro meat to soy milk) is required to explore the possible analogies and differences in their transformative potential. The broader focus allows for scrutinizing to what extent the framings and critical analyses attached to cell-based meat and milk have relevance in relation to other plant-based alternatives, and what research gaps follow from the current emphasis on technological innovation in this field of research. Although different meat and milk alternatives promote vastly different solutions to the question of protein production, their various environmental and ethical justifications share a common basis, suggesting that they may feed each other in advancing sustainable protein transition (Arppe et al. 2020).

In this paper, we review emergent social scientific peerreviewed literature carried out on both cell and plant-based meat and milk alternatives. We refer to the different product categories with an umbrella term of meat and milk alternatives. We choose this phrase to highlight the positioning of these products specifically as alternatives to the animalbased staples in Western diets; meat and milk. It is also our attempt to find a neutral denominator for such products, in order to sidestep the political and contested nature of many of the established terms (see Mouat and Prince 2018; Kramer 2015). In this vein, we purposefully choose the term alternative as a less divisive option than 'substitute', which is a term that has been actively rejected by some actors within the industry (Sexton 2016). At the same time, focusing on such a wide range of products also creates a need to define clearly the different terminologies used. Under meat and milk alternatives we separate two analytical categories, cell-based alternatives and plant-based alternatives. Cellbased (referring to in vitro meat and milk) was chosen as a neutral alternative, as the term 'cultured' relates to positive connotations such as cheese or beer culturing, whereas 'lab meat' and 'synthetic meat' has been seen as derogatory (Stephens et al. 2018a). The category of plant-based products involves all other meat and milk alternatives, ranging for example from pulse-based meat analogues with genetically engineered ingredients to textured soy protein.

The aim of the review is to assess and synthesize the social scientific research on cell-based and plant-based meat and milk alternatives in order to better understand their role within the broader protein transition. We begin the article by explicating the integrative qualitative review used for scoping out the emergent research themes. Based on our analysis of 123 social scientific journal articles on meat and milk alternatives, we show how the research anchors around three research themes, which all scrutinize the promises of these products in protein transition from very different perspectives. We scrutinize in detail the tensions identified in the studies concentrating upon market transformations, consumer preferences, politics and ethics. We end the paper by calling for more attention in future social scientific research to different plant-based solutions. This requires broadening the scope of studies from market transformation and consumer preferences to those of agricultural production, value-chains and food systems analysis.

\section{Integrative qualitative literature review}

We conducted a qualitative integrative literature review to study the emergent research themes in relation to meat and milk alternatives in the protein transition. A qualitative integrative literature review (Torraco 2016) departs from a systematic literature review (Liberati et al. 2009) by providing a more dynamic method to review literature on an emergent topic. A systematic literature review attempts to collect "all empirical evidence that fits pre-specified eligibility criteria to answer a specific research question", using explicit, systematic methods to minimize bias and provide reliable findings (Liberati et al. 2009, p. 2). Systematic review, however, is not well suited for emerging topics, such as meat and milk alternatives, which escape precise definition and have been conceptualized and defined in a varied manner. For example, in our case, the initial searches of Google Scholar quickly showcased the multitude of terms used to describe the phenomenon in question, and also that the struggle over naming was not without tensions. This showcases the ambiguities that still surround these products, which often take shape in regulatory and political conflicts. Due to this terminological ambiguity, and the range of theoretical and methodological approaches used in the studies, it would have been very difficult to perform a systematic review of the topic. Instead, the integrative review is more suitable in such cases where creative data collection methods are required (Snyder 2019). The integrative review allows for generating new knowledge about the topic under review, by synthesizing, assessing, critiquing and reflecting on representative literature on dynamic issues that experience rapid growth in literature (Torraco 2016). As the data analysis process of the integrative review is not as established on methodological terms as in the case of the systematic review, there is a need for transparent documentation of the analysis (Snyder 2019).

To carry out the review, we searched the Scopus and Web of Science databases for articles where the terms listed in Fig. 1 were mentioned in the title, abstract, or keywords of the article (in Scopus) or the Title or Topic fields (in Web of Science). The size of the terms in the word cloud in Fig. 1 shows the prevalence of articles included in the review under each search term. ${ }^{1}$

\footnotetext{
${ }^{1}$ In addition to the search terms included in Fig. 1, there were also a number of search terms that did not generate articles that met the selection criteria. These were: milk substitute, non-dairy milk, non-
} 
plant based protein

soy based

artificial meat

clean milk meat analogue

meat substitute

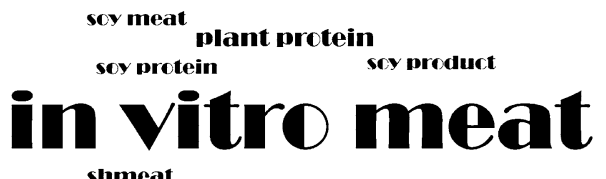

slimeat

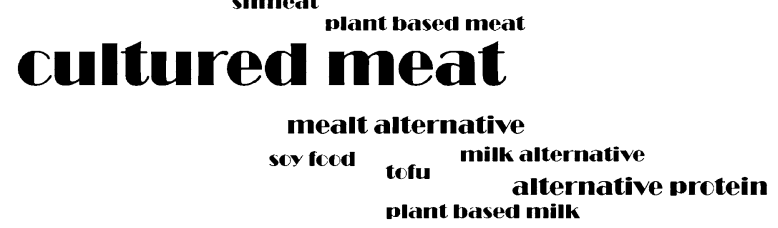

Fig. 1 Search terms that generated the articles included in the review. The size of the word signifies the number of articles that were selected based on the searches related to the term

The main selection criteria for the reviewed articles was centered on the articles' focus on products, which were clearly positioned as alternatives to meat and milk. This meant, for example, that the products were analyzed from the perspective of substitution or that their animal-based reference points (e.g. in terms of consumer experience, market presence, or ethics) were under scrutiny. The definition of the search terms was in a crucial role in the selection of the articles. We first focused on the general terms such as 'meat/milk substitute' and collected terminology from initial Google Scholar searches, while also continuously adding further search terms from the reviewed articles. Thus, new searches were made on an ongoing basis. The terminology related to the plant-based alternatives seemed to be the most ambiguous, so we also added searches focusing on specific plants or pulses to make sure all relevant articles were included. The searches for lentil and bean-based products mostly did not generate articles that had not already been included under previous search terms (e.g. 'plant-based protein'). However, searches for soy/a-based products and tofu, which we also identified as products positioned as meat and milk alternatives, generated 10 new articles for the analysis. These papers were related, for example, to the regulation and labelling of plant-based meat and milk alternatives as well as to consumer preferences of soy-based meat alternatives.

In addition, to be included, the articles had to fall into the broad category of social scientific research. In Web of Science, only articles in the Social Sciences Citation Index and Art and Humanities Index were included, while in Scopus,

\section{Footnote 1 (continued)}

meat protein, altered protein, cultured milk, synthetic milk, artificial milk, imitation meat, cellular agriculture, clean meat, and synthetic meat. the field selection was done after each search on a case-bycase basis. The other selection criteria were that articles had to be in English, appear on one of the databases between 2010 and 2019 and be either peer-reviewed journal articles or reviews. The decision to exclude older articles was supported by the novelty of the issue, as well as preliminary searches that showed that most of the relevant articles were published after 2010. As the field is constantly developing, it also needs to be noted that papers that were not found by January 2020 are not included.

We first selected papers based on title and abstract. After reading the full papers, some articles were eliminated because they did not match our main selection criteria: they did not focus on alternative products as such. This means that papers focusing on plant-based diets or eating in general were not included, if the papers did not examine specific products, categories, or innovations. Furthermore, only articles that dealt with the use of alternative proteins for human food were included. Articles that dealt exclusively with insect or algae-based foods were excluded. Papers were also eliminated if full text was not available. It should be noted that three articles are included that were found during the initial searches on Google Scholar (Sexton et al. 2019; Sexton 2016; Morris et al. 2019). These were not found on Scopus or Web of Science. In total, 2,133 articles were screened, out of which 123 articles were included in the review after the selection process (Fig. 2).

Initially, we categorized the basic information about each article (author(s), year, title, journal \& DOI, and keywords). We created two initial categories on the basis of the empirical focus of the papers: cell-based and plant-based alternatives. In reading the full papers, we also listed the empirical and theoretical focus, the research questions, the data and methods used, the results, the conclusions, and the potential research gaps which are identified.

In the analysis, it became apparent that the articles shared a consistent framing: meat and milk alternatives were presented as a promise in various dimensions: in ecological, nutritional, technological or ethical terms. This framing was often highlighted as a motivation for the studies. Beyond this shared promissory framing, the articles were situated widely across various theoretical approaches and empirical settings. As we analyzed the articles further, we classified the emergent research themes into three broad categories based on the research focus and the theoretical foundations (Table 1). The themes are (1) promissory narratives and tensions on markets, (2) consumer preferences, attitudes, and behavioral change, and (3) politics and ethics. Some themes were identified more organically than others as they dealt with parallel topics and drew from a similar theoretical background. The themes were built around our analysis of the core topics within the reviewed papers. These topics are listed in the tables preceding each theme. With regard 
Fig. 2 Selection of the articles for review

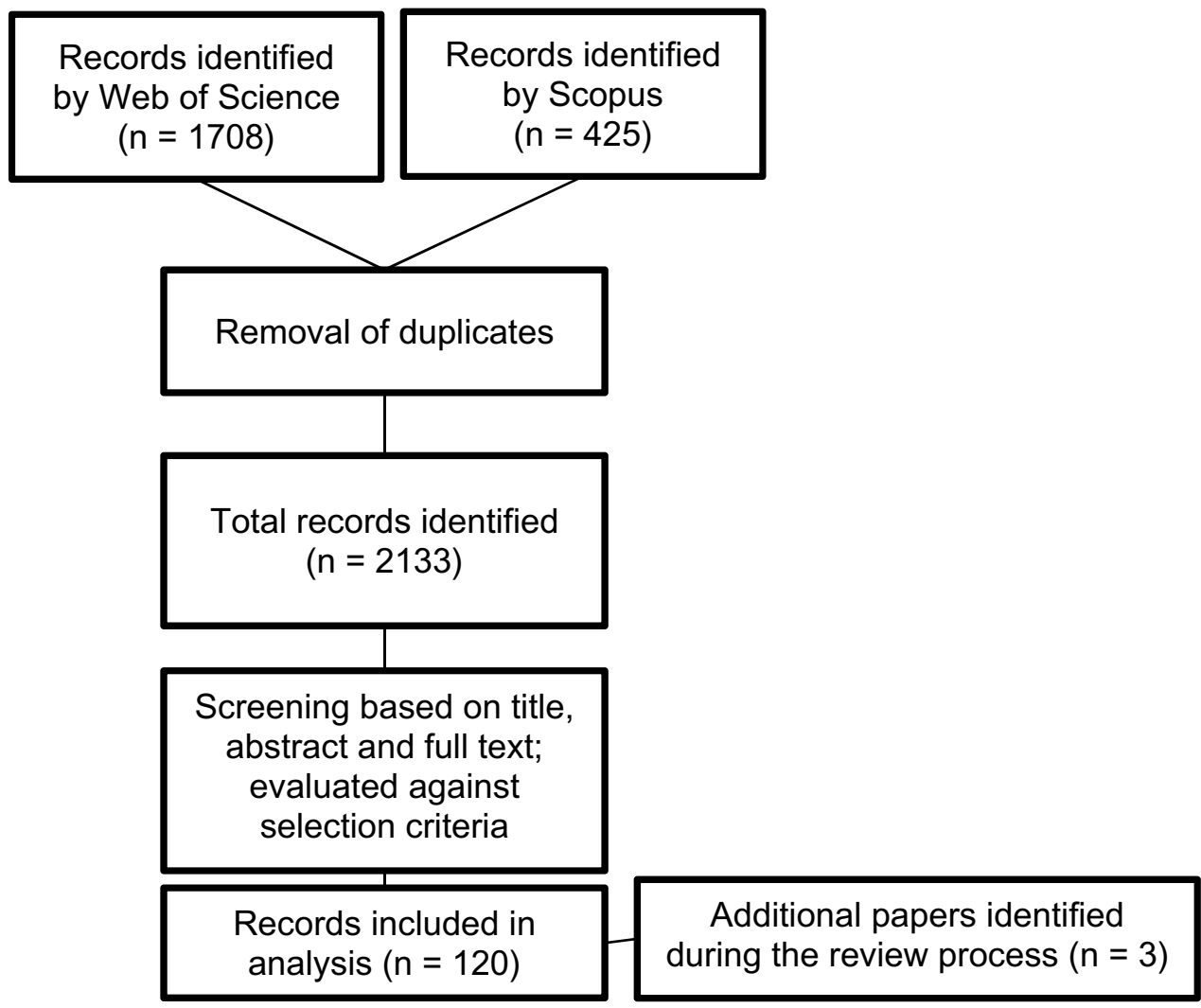

Table 1 Research themes found in the social scientific articles on meat and milk alternatives

\begin{tabular}{|c|c|c|c|}
\hline Research themes & $\begin{array}{l}\text { Plant-based meat } \\
\text { and milk alternatives }\end{array}$ & $\begin{array}{l}\text { Cell-based meat and } \\
\text { milk alternatives }\end{array}$ & The most popular journals \\
\hline $\begin{array}{l}\text { Promissory narra- } \\
\text { tives and tensions } \\
\text { on markets }\end{array}$ & 12 articles & 17 articles & $\begin{array}{l}\text { BioSocieties, } 2 \text { articles } \\
\text { Science as Culture, } 2 \text { articles } \\
\text { Meat Science, } 2 \text { articles }\end{array}$ \\
\hline $\begin{array}{l}\text { Consumer prefer- } \\
\text { ences, attitudes } \\
\text { and behavioral } \\
\text { change }\end{array}$ & 38 articles & 22 articles & $\begin{array}{l}\text { Appetite, } 15 \text { articles } \\
\text { Food Quality and Preference, } 7 \text { articles } \\
\text { Meat Science, } 5 \text { articles } \\
\text { Sustainability, } 4 \text { articles }\end{array}$ \\
\hline Politics and ethics & 8 articles & 26 articles & $\begin{array}{l}\text { Journal of Agricultural and Environ- } \\
\text { mental Ethics, } 7 \text { articles } \\
\text { Journal of Integrative Agriculture, } 2 \\
\text { European Journal of Risk Regulation, } \\
2 \text { articles }\end{array}$ \\
\hline
\end{tabular}

to the discussions within the themes, we searched for recurring topics, challenges and questions posed by the articles. We looked for both prevalence of the issues and the weight given to them in the papers. If a topic was only examined in one paper, it was generally not emphasized in the analysis. It should be noted that the classification of research themes is not exclusive. Although we have tied each article to only one theme in Table 1 (on the basis of their main focus), one article may contribute to several themes. In particular, many articles mainly focusing on other topics also call for attention to politics and ethics.

\section{Emerging research themes}

\section{Promissory narratives and tensions on markets}

The first theme anchors into a broad interest in economy and markets studying how meat and milk alternatives behave and alter food markets (Table 2). The articles explore either the narratives and discourses linked to meat and milk alternatives by various food system actors or the performativity of their marketing practices. Many authors exploring this topic draw from the theories developed within science and 
Table 2 Key empirical focuses and theoretical resources in studying promissory narratives and tensions on food markets

\begin{tabular}{ll}
\hline Empirical focus & Key theoretical resources \\
\hline Promissory narratives and discourses used by various actors in industry, media and academia & Science and technology studies \\
Market/ing practices and performance & Performative economics \\
Evaluation of transition pathways & Socio-technical transitions \\
Ontological tensions in promissory narratives & Economic geography \\
Regulatory questions arising from the ontological tensions related to meat and milk alternatives & \\
\hline
\end{tabular}

technology studies, performative economics or socio-technical transitions.

Several papers turn critical attention to how different actors such as the meat and milk alternative industry and its funders (Murray 2018; Sexton et al. 2019; Stephens et al. 2018a, b; Morris et al. 2019), academia and media (Stephens 2013; Jönsson 2016; O’Riordan et al. 2017; Stephens and Ruivenkamp 2016; Goodwin and Shoulders 2013; Dilworth and McGregor 2015; McGregor and Houston 2018; Buscemi 2015), or the meat industry (Keefe 2018; Bonny et al. 2015; Boler and Woerner 2017) construct the promissory narratives in their discursive and material practices. These studies show how the promise of meat and milk alternatives is presented as one of 'techno-salvation', nothing less than a kinder, healthier, fairer, tastier, safer, and more sustainable food system for all (Sexton et al. 2019). Fuentes and Fuentes (2017) show how milk alternatives draw on similar ethical and ecological justifications as alternative food networks; whereas Murray (2018) investigates how engineers of new foodstuffs incorporate ethics into them as a means to pave the way for wider public acceptance. Especially in relation to cell-based alternatives, which exist so far more as fictions than tangible foodstuffs (Sexton et al. 2019; Mouat and Prince 2018), it is easy to see why the promises have also gained academic attention as an empirical object of study.

Stephens et al. (2018b) emphasize that all technological innovations are embedded within sets of promissory narratives and future imaginaries. Building on the literature on the sociology of expectations (Brown and Michael 2003), various authors (Jönsson 2016; Stephens and Ruivenkamp 2016; Stephens 2013; Sexton et al. 2019; Stephens et al. 2018b; Ferrari and Lösch 2017) explore how promissory narratives work in establishing a framework of meanings around meat and milk alternatives, and enroll financial, institutional, and public support for them. This helps to underline the material and political work taking place in the present time frame to pave the way for new innovations. While there still exists considerable uncertainty related to these promises, the discursive weight of the various textual and material tools harnessed in their marketing contribute to their normalization (Mouat and Prince 2018, p. 317). In other words, through performative acts, expectations help bring into being the world they describe (Brown and Michael, 2003).
The promissory narratives of meat and milk alternatives highlight diagnosed issues within intensive livestock agriculture, related for example to food safety, ethics, or the environment. Stephens et al. (2018b) call this the crisis narrative of the alternatives. Building on performative economics (Callon 2007), Mouat and Prince (2018) portray the making of alternative markets as the managing of the negative overflows of animal agriculture. Mouat and Prince (2018) suggest that the promissory narratives have a form of agency of their own, and through problematizing animal agriculture, they work to continuously affirm the market for animal-free alternatives. Similarly, Sexton (2016) showcases that meat alternatives are constantly portrayed as what they are not, as the non-stuff of which they consist. In this way, the papers showcase how the market for meat and milk alternatives becomes constituted against animal agriculture and, hence, inseparably entangled with it.

Furthermore, these narratives build upon the notion that meat and milk are necessary components of human diets. Murray (2018) relates how at a tasting event for the cultured meat burger, advocates drew on human evolutionary history and psychology in establishing humans as a meat-eating species. This narrative works to normalize the high rates of meat consumption as the natural predisposition of humans. This also relates to nutrition: Jönsson et al. (2019) show how, in the marketing of milk alternatives, the position of milk as a desirable, complete source of nutrition becomes continuously reasserted. Similarly, cultured meat is promised to offer the same nutrition and morale boost as conventional meat (Jönsson 2016). The narratives also highlight the similarity in taste and consistency in relation to meat and milk. Sexton (2018) notes that the developers of meat alternatives see the lack of familiarity, mouth-feel and taste as the biggest barriers to the consumption of alternatives.

The critical analysis of the promises attached to meat and milk alternatives highlight the complex relationship between animal-based and animal-free foodstuffs. The reviewed papers underline a profound tension between assuring similarity and asserting difference between these products. Animal agriculture is at the same time both the source for potential consumers of meat and milk alternatives and their "essential constitutive outside" (Mouat and Prince 2018 , p. 319). This tension is also identified in relation to the meat and milk alternatives already on the market (Fuentes 
and Fuentes 2017; Mylan et al. 2019; Jönsson et al. 2019; Morris et al. 2019; Ledin and Machin 2019). Examining the marketing of oat-milk company Oatly, Fuentes and Fuentes (2017) show how the company engages in a simultaneous "alternativisation and conveniesation" (p. 531) of its products, producing a compound and plastic product potentially capable of attracting consumer groups with varying interests. Oatly is simultaneously entangling alternative values and conventional market mechanisms. Ledin and Machin (2019) find that Oatly does not really tackle the details of the political issues with which they align, while simultaneously opening an avenue for consumers to engage in social activism through purchasing. This easy and fun activism-lite can nonetheless give consumers a powerful sense of being part of a political moral order (Ledin and Machin 2019).

Mylan et al. (2019) also examine the tensions in the case of plant-based milks showing the difficulties encountered in practice (see also Morris et al. 2019). Drawing on sociotechnical transition studies (Geels 2004; Smith and Raven 2012), they show how the initial 'rage against the regime' was watered down into a product reform, where the functioning of the food system (in relation to the organization of food markets, retail and consumption) remained largely unchanged. This outcome differed from the visions of the social movement behind the campaigns for plant-based milk, which championed radical changes in the organization of the agri-food system. Mylan et al. (2019) conclude that the trajectories of plant-based milks in the UK market followed hybrid 'fit' and 'stretch' patterns, contributing to both incremental reform and substantial transformation between changing sites and environments.

The tension inherent in the promissory narratives of meat and milk alternatives has led also to conflicts related to ontological questions as well as regulatory categories. What exactly is meat or milk? The tension of being both the same and different renders meat and milk alternatives ontologically muddy. Aiming to dethrone animal-based agriculture is a radical engagement in conflict with other realities. While stating that plant-based milk simply is milk can be perceived as an attempt to co-exist with dairy milk-and even to reinforce dairy milk or meat as the norm-there is also conflict involved, the reviewed papers show. The statements that assert similarity between animal-based foods and alternatives have been strongly countered by stakeholders within animal agriculture (Keefe 2018; Boler and Woerner 2017; Bonny et al. 2015). Questions about the appropriate terminology to be used in marketing and labelling in relation to the alternatives have also led to regulatory battles (Stephens et al. 2018a; Petetin 2014; Lee 2018; Bhat et al. 2019; Carreño and Dolle 2018; Bolton 2017). Within the $\mathrm{EU}$, it is currently prohibited to use protected terms such as 'milk' or 'cheese' for plant-based products even when preceded by specifications of their plant origin. With meat, similar restrictions do not currently apply on the EU level (Carreño and Dolle 2018; Bolton 2017). ${ }^{2}$ The studies call for further clarification of the EU regulatory structures for cell-based meat and milk and more generally for novel foods (Petetin 2014). The ambiguities related to the use of genetically modified cell-lines make it difficult to situate in vitro meat in the existing regulatory context. Jönssön et al. (2019) also re-emphasize that expectations of peaceful co-existence between animal-based foods and alternatives may be unfounded, as commodities tend to attempt to take over each other's shares in the market. Thus, these studies reveal painstakingly how neither of these realities-co-existing with or dethroning meat and dairy-will take shape easily.

Furthermore, the fact that empirical cases show the promise of meat and milk alternatives to be both similar to and different from animal-based foods also signifies a move away from the division between niche-marketing and "normalizing sustainability for the masses" (Fuentes and Fuentes 2017 , p. 548 citing Rettie et al. 2012). The inherent tension can also be crafted into a multi-niche approach (Fuentes and Fuentes 2017), where actors draw on various alternative qualities, allowing them to maintain their politicized and subversive identity without sacrificing their appeal to large consumer segments. Whether this hybridity enhances or diminishes the transitional potential of meat and milk alternatives is not yet clear on the basis of the reviewed studies. As explicated by Mylan et al. (2019), the 'rage against the regime' petered out through the selective appropriation of the radical elements of plant-based milks by the regime. However, co-existing meat and milk alternatives may still carry transitional potential as Trojan horses, luring regime actors into transitional practices, as Pel (2016) notes, by helping to bridge contested boundaries between the diets and identities attached to animal-based and alternative foods.

\section{Consumer preferences, attitudes and behavioral change}

Within the second research theme, the research interest lies in consumer preferences or attitudes towards the alternative products on the market (Table 3 ). The articles scrutinize consumer perceptions, attitudes and behavioral change mainly from the point of view of individual choice or preferences. Studies also assess behavioral change policies to support the use of these products as part of shifting diets. The studies on consumer preferences draw on social psychology,

\footnotetext{
2 Although the articles included in the review focused on the EU, it should be noted that the U.S. livestock industry has also pushed for stricter regulation on the use of terms such as 'meat' or 'beef' on the grounds of potentially misleading consumers (Sachs and Kettenmann 2019). In recent years, various truth-in-labelling laws have been passed in many U.S. states (Tai 2020).
} 
Table 3 Key empirical focuses and theoretical resources in studying consumer preferences, attitudes and behavioral changes

\begin{tabular}{ll}
\hline Empirical focus & Key theoretical resources \\
\hline Barriers and facilitating factors for choosing meat and milk alternatives & Social psychology \\
Attitudes towards meat and milk alternatives & Behavioral sciences and behavioral economics \\
Sensory attributes of meat and milk alternatives & Cognitive and sensory sciences \\
The most effective promotion and marketing strategies & \\
Socio-economic differences in consumer preferences, attitudes and eating & \\
Behavioral change and policies & \\
\hline
\end{tabular}

behavioral sciences and economics as well as cognitive and sensory studies.

In analyzing various facilitating factors and barriers for consumption and acceptance of alternatives, the studies on consumer preferences give insight into how consumers perceive and value the various promises attached to alternatives. First, moral and ethical promises are found to be important for increasing the acceptance of cell-based meat and milk alternatives (Circus and Robison 2019; Verbeke et al. 2015a). However, the studies highlight that these promises do not necessarily lead to willingness to choose or consume the alternatives. Instead, consumers value various ethical, environmental, and societal benefits on a broader level, such as in relation to global food security (Verbeke et al. 2015a; Hocquette 2016; Lupton and Turner 2018). A framing centered on ethical, environmental, and societal benefits of the cell-based alternatives is thus likely to contribute to positive attitudes towards cultured meat (Bryant and Dillard 2019), but it is unclear how it would affect willingness for personal consumption. The studies also identify various concerns and uncertainties in consumer acceptance when cell-based alternatives hit supermarket shelves, especially related to food neophobia (Wilks et al. 2019), disgust (Verbeke et al. 2015a; Wilks et al. 2019), anticipated inferior taste (Tucker 2014; Bryant and Barnett 2018), perception of unnaturalness (Lupton and Turner 2018; Tucker 2014; Siegrist et al. 2018; Verbeke et al. 2015a) and anticipation of risks to human health (Siegrist and Sütterlin 2017; Egolf et al. 2019). At the same time, the novelty factor generates interest towards new products (Van der Weele and Driessen 2013; Circus and Robinson 2019).

Studies examining consumer attitudes and behavior in relation to plant-based alternatives show slightly different results. Moral and ethical reasons (Clark and Bogdan 2019; Circus and Robinson 2019) and promises related to human health (Elzerman et al. 2013; Vainio et al. 2016; Bosman et al. 2011; Farrell et al. 2019; Moon et al. 2011; Palmer et al. 2018; Tu et al. 2012) are found to facilitate consumer acceptance of plant-based foods. Weinrich (2019), however, concludes that while these promises may encourage consumers to try plant-based alternatives, they are less likely to influence regular consumption. For meat alternatives to become stables in diets, taste and other positive sensory aspects are the main factor (Hoek et al. 2011; Elzerman et al. 2013; Clark and Bodgan 2019; Weinrich 2019). Specifically, the promise of similarity to meat and milk in relation to both taste and nutrition facilitates the use of processed meat alternatives (Hoek et al. 2011) and plant-based milks (Haas et al. 2019). Similarity to the user interface and application in meals is also valued, in terms of convenience (McBey et al. 2019; Elzerman et al. 2013), conformity, ease and fit with current lifestyle (Apostolidis and McLeay 2016).

Existing eating motives, habits and prior beliefs play an important role in consumer willingness to ingest or accept meat alternatives or reduce meat consumption (Vainio et al. 2016, 2018; Hartmann and Siegrist 2017; Weinrich 2018). Consumers have also been found to use symbolic information when evaluating foods, potentially leading to biased judgments (Siegrist and Sütterlin 2017). For example, those unwilling to reduce meat consumption are less likely to believe that livestock agriculture contributes to climate change (Malek et al. 2019), and absolute opposition to cultured meat is predicted by conspiratorial ideation (Wilks et al. 2019). Furthermore, consumers who distrust science and have concerns related to the governing of risks (Verbeke et al. 2015a; Wilks et al. 2019), are less likely to accept cell-based meat and milk alternatives. In addition to prior beliefs, existing eating habits and skills influence the openness of consumers to including meat and milk alternatives in their diets. For example, a lack of cooking skills has been identified as a barrier to the use of plant-based meat alternatives, also involving legumes (Graça et al. 2019; Palmer et al. 2018). ${ }^{3}$

The reviewed articles also suggest that different consumer groups have different capacities and interests towards meat and milk alternatives. This line of research links to the focus

\footnotetext{
3 Although highlighting the importance of skills, the reviewed articles pay less attention to the (material) practices of eating and consumption. For example, research inspired by practice theories highlights that beliefs and attitudes about food are only translated into food practices through the shared, material and even visceral relations in everyday life (see, for example, Goodman 2016; Hayes-Conroy and Hayes-Conroy 2010, 2013; Kaljonen et al. 2020; Peltola et al. 2020; Plessz and Wahlen 2020; Warde 2016). Thus, one should be wary of drawing conclusions related to manifested eating practices based on the reviewed studies focusing on attitudes and opinions on eating. The more practice-oriented studies may have been excluded from the review due to the focus on products in the search terms.
} 
on socio-economic differences in eating in consumer studies. For example, male, politically liberal (Wilks and Phillips 2017) and urban (Shaw and Iomaire 2019) consumers tend to be more receptive to cultured meat, while vegetarians are more wary than other consumer groups (Verbeke et al. 2015b; Wilks and Phillips 2017). It is important to note that both contextual and individual factors impact protein consumption (de Boer and Aiking 2018). For example, life course differences influence the willingness to consume plant-based proteins, especially with new mothers (McBey et al. 2019). Issues of availability and affordability are also potential issues for some consumer groups (Clark and Bogdan 2019).

The reviewed articles also consider how consumer acceptance of these products should be promoted. The studies underline that for the cell-based products, contested issues, such as naturalness, should be avoided altogether, focusing instead on the similarity of the product to conventional meat (Bryant and Dillard 2019; Siegrist et al. 2018). Overall, it is suggested to be more beneficial to focus on removing the barriers to consumption rather than enhancing awareness and acceptance of facilitating factors (e.g., health promises; Wansink et al. 2014). These claims build upon recent interest in behavioral sciences in giving more attention to intuitive, fast thinking in people's choices when designing behavioral change policies (Kahneman 2011; Thaler and Sunstein 2008). In the case of meat and milk alternatives, attention is turned specifically to the role of substitution as a strategy for supporting incremental change (Schösler et al. 2012). Substitute products, which closely mimic animal-based foods, can also persuade the most difficult consumer group, the taste-driven segment, with which "sustainability-bystealth" may be required (Apostoloidis and McLeay 2016, p. 84). Manageable substitution strategies may also involve mixed dishes with both animal and animal-free protein (de Boer and Aiking 2019). Furthermore, substitution can help bridge dietary boundaries based on prejudices or identity politics (Morris et al. 2019), as both those who refuse animal products and those who reduce them would be impacted by strategies and policies related to substitution. Promoting small and manageable changes also contributes to maintaining dietary change over time and may increase the acceptance of meat reduction strategies across consumer groups (Vainio et al. 2016). Overall, many of the reviewed articles call upon policies and regulation to build an "infrastructure of consumption" that ensures that the sustainable choices are also the easy choices (Lee 2018, p. 36).

Considering the general contribution of consumer research, it should be noted that very little long-term research on the consumption of meat and milk alternatives is yet available (Weinrich 2019), and it is thus difficult to evaluate how consumer acceptance develops over time, or how alternatives become staple diet components.

\section{Politics and ethics}

Many of the reviewed individual empirical articles raise the importance of politics and ethical considerations in their conclusions, when discussing the implications of their results (Table 4). In particular, the cell-based alternatives demand ethical reasoning.

There is wide consensus among ethicists that the contemporary practices of meat production are morally corrupt. In other words, moral agents must consider alternatives regardless of the moral theory to which they adhere (Pluhar 2010). For Pluhar (2010), this means that it is difficult to find objections to cultured meat if it would be affordable and available to all, and if the animals involved would be treated with the utmost respect. There exists, however, intense debate in ethics regarding whether cell-based meat alternatives are problematic in terms of animal dignity (Milburn 2018, 2016; Schaefer and Savulescu 2014; Cole and Morgan 2013; Chauvet 2018). Animals are still in some instances used to produce fetal bovine serum, extracted from unborn fetuses in slaughtered pregnant cows as a by-product of dairy production (van der Valk et al. 2018). However, the industry is largely committed to replacing the serum with a synthetic alternative, which is expected to soon replace animal-based media for cell-based meat (van der Valk et al. 2018). Many of the articles in the review discuss whether the use of these few animals can be ethically justified (Chauvet 2018; Cole and Morgan 2013; Pluhar 2010).

The reviewed articles also discuss the ethical question on the flip side: are farm animals harmed by not being brought into existence due to reduction in meat consumption? The answer depends on the quality of life of farm animals. Schaefer and Savulescu (2014) suggest that an ethical version of cell-based meat should promote the simultaneous strengthening of 'happy farming' practices. Whereas, Laestadius (2015) argues that the development of cellbased alternatives is only ethical if they are more effective
Table 4 Key focuses in ethical questions and reasoning

\begin{tabular}{ll}
\hline Focus of ethical reasoning & Theoretical resources \\
\hline Ethics of animal-based food systems & Moral philosophy \\
Animal dignity & Science and Technology Studies \\
Technological development and relationship to animals and nature & Political economy and ecology \\
Power relations in agri-food and innovation systems & Social Psychology \\
Diversity of ethical questions and openness in their discussion & Media studies \\
\hline
\end{tabular}


at reducing conventional animal meat consumption than plant-based alternatives. Also, the ethical questions of cannibalism are addressed: what if the material used for culturing comes from consenting human donors (Majima 2014; Milburn 2016; Schaefer and Savulescu 2014).

In addition to the problematic connection of cell-based technological solutions to animals, researchers pay attention to the cultural and symbolic implications of meat alternatives. Cole and Morgan (2013) and Dilworth and McGregor (2015) argue that cell-based meat reproduces the fetishization of meat, where meat retains a privileged position in our diets and appetites. Similarly, Chauvet (2018) is concerned that plant-based meat alternatives also fetishize meat, attempting to imitate a "cooked dead animal's body: its taste, texture, physical appearance, smell, and, sometimes, name" (p. 401). Milburn (2018) agrees that in relation to meat, cultured products reinforce the meat norm but argues that our relationship with milk is different. Whereas meat exists first and foremost not as food, but as an animal body, it can be seen as morally wrong to perceive meat as a resource. Milk, on the other hand, exists solely as food. Mammals' milk is produced to feed offspring, and milk-sharing practices are widely accepted in most human and animal cultures.

Most papers focusing on ethics also touch upon the question of alienation from nature. According to Alvaro (2019), cultured meat should not be supported because it stems from unvirtuous motivations, one of which is that it alienates us from the natural processes of food production. This argument rests on the idea that cell-based meat alternatives substitute the interdependence of humans and nature by total independence (Schaefer and Savulescu 2014), fundamentally altering our place in the world. It can also be said that these alternatives treat nature only as a means to an end to fulfill our needs, "rather than a partner" (Schaefer and Savulescu 2014, p. 191). Technological solutions easily push nature and animals into the background, and as a result, the ethical issues also related to our relationship with meat, are hidden from view (Galusky 2014).

Ethical scholars call for openly confronting the ethical questions of engaging with animals, humans and ecologies of food, instead of turning them into engineering ones. Dilworth and McGregor (2015, pp. 103-104) argue that the most common ethical issues attached to cultured meat (related to environment, animal welfare and food security) "lend themselves to relatively straightforward cost-benefit analysis", while the more pressing issues related to food justice, animal liberation, techno-skepticism and socio-ecological harmony require much more careful consideration. The authors worry such questions will only be fully explored once the products become publicly available, when it may already be too late. Metcalf (2013, p. 83) also urges scholars to focus on the disconnection inherent in the framing of cell-based meat and milk alternatives as technical fixes "to the disastrous relations between humans, animals, land and sustenance". Stating that "there is no way to engineer the world out of technoscience" Metcalf hopes that we instead learn to "take pleasure in and responsibility for the messy processes that sustain life". For van der Weele and Driessen (2013), the future of cell-based meat alternatives does not have to sever our relations with livestock animals. They propose a model for ethical relations called "a pig in the backyard" (van der Weele and Driessen 2013, p. 655). In this model, cultured meat is imagined as "an element of a hybrid community of humans and animals that would allow for both the consumption of animal protein and meaningful relations with domestic (farm) animals" (p. 647). The authors call for the inclusion of a larger set of moral identities in the discussion about the future of meat and suggest that aesthetics and affective experiences must also play a role here.

The reviewed articles also focus on global political economy and the issue of food security and justice. Alternative products are seen to have the potential to play a useful role in meeting predicted increases in the global demand for meat (Kadim et al. 2015). However, there is a need to pay closer attention to the political economies of alternatives, for example, the extent to which they take up the challenge of the unequal distribution of protein-rich foods and diets geographically. Sexton (2018) also questions whether alternative proteins are able to disturb existing economic or power structures within the agri-food system. Majima (2014) argues that there is a cause to pay closer attention to the patents and ownership structure behind cell-based meat. Cole and Morgan (2013) also express concern over the antidemocratic biotechnological future of food promoted by cell-based meat and milk alternatives.

In this vein, the studies call for more attention to political processes that contribute to inertia within decisionmaking in food markets and policy. In studying political stakeholders' ideologies in relation to in vitro meat, Chiles (2013) found that ideology works as an "indispensable interpretive resource" (p. 479) in navigating the potential conflicts and controversies around cell-based meat. Specifically, ideologies which support the idea that technological innovations will fix the matters of unsustainable food consumption and processes must be critically evaluated. A focus on technological innovations may stem from deeply ingrained assumptions about the ideal of ultimate control over food production, depending on highly integrated models of industrial organization (van der Weele et al. 2019). It is also highlighted that the moderate to high degrees of social-institutional change required by the technologicallyintensive alternatives may be difficult to achieve solely through a technological focus (ibid.). In other words, an economically viable, cell-based meat sector could be created, but it may not deliver all of the more altruistic or socially and environmentally benefits currently associated with it 
(Stephens et al. 2018a). Governance structures focused on just and sustainable principles are crucial in order to ensure that novel future realities of food correspond to the promises attached to meat and milk alternatives (Stephens et al. 2018a; van der Weele et al. 2019). For example, cell-based products could be evaluated based on how well they contribute to participatory democratic processes, transparency, corporate responsibility, and sustainability goals (Lee 2018).

In this vein, more critical attention should be paid to the role of 'Big Tech' in designing the future of food-and its transformative potential, as well as lack of it (van der Weele et al. 2019). This is especially crucial considering that it is pulses, rather than cell-based technological innovations, that may offer the most potential for altering agricultural practices at the same time (van der Weele et al. 2019). Pulses, however, lack political and economic support and suffer from neglect of attention, money, human resources, as well as scientific capacity. Other research also underlines that there is a further need to clarify the position of legumes and also highlight their sustainability potential in dietary guidelines (Figueira et al. 2019; Havemeier et al. 2017). However, changing the direction of research and innovation programs is difficult, due to vested interests, division of labor and silothinking (van der Weele et al. 2019).

\section{Discussion}

As the methodological section of the review shows, determining how to define the topic of meat and milk alternatives has not been straightforward. The field is continuously developing as new products emerge on the market or are invented in the lab. Neither is the terminology related to the new foodstuffs yet fixed. However, we feel it has been crucial to attempt to collect the whole field of alternatives together, ranging from plant-based to cell-based products. Furthermore, the inclusion of milk alternatives allows us to highlight the analogies between meat and milk alternatives and suggest that much can be gained from analyzing these alternatives together in the framework of the main animalbased staples of Western diets. Analyzing the whole field of alternative proteins together allows us to explicate that a fundamental feature of the alternatives is their inescapable connection both to the attributes of meat and milk and the crisis of livestock production, from which a fundamental ontological tension follows. The collective analysis of the alternatives turns attention also to the perspectives that have so far received less attention in the discussion over sustainable protein transition.

The articles within this review stem from very different theoretical foundations. The three research themes identified (market transformation, consumer preferences, and politics and ethics) portray distinctively different promissory narratives for these products in relation to protein transition. First, studies focusing on the tensions in the markets highlight the ontologically hybrid and contested nature of meat and milk alternatives. These studies show how the new products aim to be positioned both the same and different from their animal-based counterparts. The tension calls for further attention to ontological politics in understanding the protein transition, in order to make sense of how disruptive firms interact with established actors in contested relations. The notion of ontological politics relates to the understanding that practices produce effects in reality (Mol 1999) that contribute to multiple interlinked realities and ultimately multiple worlds. In understanding what meat and milk alternatives do, and can do, in relation to the protein transition, it is important to continue to focus on how the ontological battles over their identity and reference points are carried out in specific contexts and for specific products. These battles can reveal crucial barriers and facilitating factors for sustainable protein transition.

Second, the consumer studies suggest that consumer acceptance is influenced by everyday practices, such as skills, and sensory expectations and experiences, yet these studies also touch upon the question of ontological ambiguities. Consumers want delicious, simple products that they know how to cook; the attributes that are attached to meat and milk. Thus, the conclusion is often that in order to get consumers on board to protein transition, it is important to produce alternatives that resemble meat and milk as closely as possible. At the same time, such thinking can work to emphasize the role of meat and milk as superior food against which other protein products are compared. The latter is emphasized by the review as one of the key ethical dilemmas put forward by the meat and milk alternatives.

Third, bringing together articles that raise ethical and political questions over a variety of alternative products also highlights how different products are attached to different promises, ethics, and visions of the future of food and proteins. Turning attention to these questions allows for a more critical analysis of the alternatives-analysis that looks beyond the disruptive hype surrounding the products into the visions for future food systems with which they are embedded and to which they contribute. Attention needs to be paid to how different meat and milk alternatives are entangled with the destructive consequences of capital-intensive agriculture on global food security, as well as to the power extended to biotechnology companies over food production and distribution through some meat and milk alternatives.

In this respect, the review contributes to further understanding of the promises related to meat and milk alternatives and the protein transition, which highlights the need for an urgent move away from reliance on animal-based protein (de Boer and Aiking 2018; Tziva et al. 2020). The review 
makes explicit how the current studies on meat and milk alternatives often highlight the transformative potential of technological innovations within the protein transition. Our analysis suggests that the inescapable ontological tension inherent in meat and milk alternatives does not necessarily do justice to plant-based products. When technological innovation is highlighted as the key to the protein transition, it is often assumed that improved product quality signifies increased similarity to meat or milk. Integrating pulses and plant-based products within the comprehensive review on alternative proteins reveals, however, that there is little sense in holding meat and milk as the ultimate reference point for all protein products. Plant-based alternatives may have the potential to develop more complex connections to conventional meat than cell-based products-purposefully moving away from the narrative of similarity that reinforces the nutritional, cultural, and social significance of animal protein. Furthermore, they may also help to raise critical questions about the overconsumption of animal protein in Western diets. For example, further research could focus on the need to couple reduction in animal-based protein consumption with the development of alternative proteins.

Plant-based alternatives highlight how similarity to meat and milk consists of different material practices that are not necessarily all engaged with simultaneously. For example, plant-based alternatives may attempt to correspond to meat or milk in relation to the user interface, while attempting to transform consumer preferences in relation to structure and taste. Furthermore, new associations may be needed in order to attach plant-based proteins as well to "festive, fulfilling, energizing, and pleasurable food" (Jallinoja et al. 2016 , p. 12). We argue that focusing too heavily on increasing the similarities between alternatives and animal-based food, or equating technological innovation with quality or success may unnecessarily narrow down and foreclose the imagined future realities of the protein transition. They may also foreclose discussions about the necessary reductions in the overall protein consumption levels in Western diets. Further work could build links with existing research on food practices in order to better understand how individual products become staples in our diets and shared practices of eating (see, for example, Goodman 2016; Hayes-Conroy and Hayes-Conroy 2010, 2013; Kaljonen et al. 2020; Plessz and Wahlen 2020; Warde 2016). Currently, research on alternative products and eating practices are largely carried out within different realms (although see e.g. House 2019, Peltola et al. 2020 as exceptions).

Specifically, we argue that the ontological tension that exists within meat and milk alternatives should not be allowed to guide policy measures for the protein transition. Furthering protein transition is often seen best achieved by supporting more sustainable technological innovation (Tziva et al., 2020). Due to vested interests, this might be politically more feasible, compared to turning focus to restructuring agricultural practices, supporting new value chains or taxing consumption. As mentioned, a focus on technological innovation may also direct policy towards less sustainable options (van der Weele et al. 2019). Social scientific research is in a crucial role to explore how meat and milk alternatives re-invent and re-imagine agricultural and other practices within the food system, as well as our relationship with land and sustenance. Such research could also support finding more comprehensive policy measures for the protein transition (Huan-Niemi et al., 2020; Mason and Lang, 2017).

The review makes explicit that currently, most of the studies on meat and milk alternatives stop at the farm gate. In other words, the impacts of the proposed frameworks of the future attached to alternatives to farming practices and communities are rarely examined. In the current social scientific studies, the journey of plant-based alternatives may be followed from industry to retail shelf and to the consumers' plate, but rarely to the farm and field. In order to tackle transformation on the scale of the food system, re-focusing attention toward production and the whole food system is needed. Pulse-based and grain-based alternatives are entangled with changing practices of contemporary food production and processing in ways that differ from cell-based alternatives. Meanwhile, there is also concern over the lack of consideration for the fate of rural societies in the narratives around cell-based meat alternatives (McGregor and Houston 2018). So far, little attention has also been paid to the future of human-livestock relations in the various promises of meat and milk alternatives. The consequences of a post-animal revolution built on cultured meat from which the animals have been engineered out (Metcalf 2013) are unclear both for the livestock animals and our relationships with them. Although as yet largely underexplored, these questions are critical with regard to meat and milk alternatives.

On the basis of the review, we suggest that the potential of plant-based products to re-entangle rather than disentangle the links between our protein production, agriculture and land, require further empirical rigour. Plant-based alternatives can have significant potential to complement, diversify or even replace livestock production with introducing more diverse crops to our production systems and diets; whilst improving human and soil health in the meantime.

\section{Conclusions}

The field of meat and milk alternatives is developing fast as a topic for social scientific research. Examining alternative products contributes to research focusing on sustainable protein transition, showcasing the potential of individual 
technologies or products in changing both our food consumption and production. At the same time, analyzing the alternatives in a comprehensive manner is crucial for teasing out the fundamental features and inherent complexities of the alternative futures proposed by the products.

Based on the review, meat and milk alternatives hang in an inescapable tension with conventional meat and milk. They are manifested as what they decisively are not (related to the negative impacts of meat and milk), but also as what they hope to be (closely attached to the desired qualities of meat and milk). Enhancing the normative status of meat and milk in Western diets can be detrimental, as overconsumption is a crucial issue. Facing the need to move towards more plant-based, or even animal-free, food systems, can the alternatives afford to sustain such a referential identity? Distancing themselves from animal-based food as the reference point may be necessary for establishing either cell-based or plant-based alternatives as diet staples and contribute to durable change within food systems. Furthermore, beyond the promissory narratives attached to them, it is crucially important that social scientific research explores the material realities of the future of food that scaling up would generate for the alternatives.

Supplementary Information The online version contains supplementary material available at https://doi.org/10.1007/s10460-020-10184 -9.Acknowledgements We would like to thank Academy of Finland Project No. 315897 and Strategic Research Council of Academy of Finland Project No. 327284 for funding our work. We thank also the three anonymous referees for their comments, which helped to improve the article.

Funding Open Access funding provided by Finnish Environment Institute (SYKE).

Open Access This article is licensed under a Creative Commons Attribution 4.0 International License, which permits use, sharing, adaptation, distribution and reproduction in any medium or format, as long as you give appropriate credit to the original author(s) and the source, provide a link to the Creative Commons licence, and indicate if changes were made. The images or other third party material in this article are included in the article's Creative Commons licence, unless indicated otherwise in a credit line to the material. If material is not included in the article's Creative Commons licence and your intended use is not permitted by statutory regulation or exceeds the permitted use, you will need to obtain permission directly from the copyright holder. To view a copy of this licence, visit http://creativecommons.org/licenses/by/4.0/.

\section{References}

Alvaro, C. 2019. Lab-grown meat and veganism: A virtue-oriented perspective. Journal of Agricultural and Environmental Ethics 32: 127-141.

Apostolidis, C., and F. McLeay. 2016. Should we stop meating like this? Reducing meat consumption through substitution. Food Policy 65: 74-89.
Arppe, T., M. Niva, and P. Jallinoja. 2020. The Emergence of the Finnish edible insect arena: The dynamics of an 'active obstacle.' Geoforum 108: 227-236.

Bhat, Z.F., J.D. Morton, S.L. Mason, A.E.-D.A. Bekhit, and H.F. Bhat. 2019. Technological, regulatory, and ethical aspects of in vitro meat: A future slaughter-free harvest. Comprehensive Reviews in Food Science and Food Safety 18 (4): 1192-1208.

Boler, D.D., and D.R. Woerner. 2017. What is meat? A perspective from the American Meat Science Association. Animal Frontiers 7 (4): 8-11.

Bolton, B. 2017. Dairy's monopoly on words: The historical context and implications of the TofuTown decision. European Food and Feed Law Review 12: 422-430.

Bonny, S.P.F., G.E. Gardner, D.W. Pethick, and J.-F. Hocquette. 2015. What is artificial meat and what does it mean for the future of the meat industry? Journal of Integrative Agriculture 14 (2): 255-263.

Bosman, M.J.C., S.M. Ellis, J.C. Jerling, J. Badham, and D. van der Merwe. 2011. South African consumers' opinions and beliefs regarding the health benefits of soy and soy products. International Journal of Consumer Studies 35 (4): 430-440.

Brown, N., and M. Michael. 2003. A sociology of expectations: Retrospecting prospects and prospecting retrospects. Technology Analysis \& Strategic Management 15 (1): 3-18.

Bryant, C., J. Barnett, and J. . 2018. Consumer acceptance of cultured meat: A systematic review. Meat Science 143: 8-17.

Bryant, C., and C. Dillard. 2019. The impact of framing on acceptance of cultured meat. Frontiers in Nutrition 6: 103.

Buscemi, F. 2015. New meat and the media conundrum with nature and culture. Lexia 19-20: 419-434.

Callon, M. 2007. What does it mean to say the economics is performative? In Do economists make markets?, ed. D. MacKenzie, F. Muniesa, and L. Siu, 311-358. Princetown: Princetown University Press.

Carreño, I., and T. Dolle. 2018. Tofu steaks? Developments on the naming and marketing of plant-based foods in the aftermath of the TofuTown judgement. European Journal of Risk Regulation 9 (3): $575-584$

Chauvet, D.J. 2018. Should cultured meat be refused in the name of animal dignity? Ethical Theory and Moral Practice 21: 387-411.

Chiles, R.M. 2013. Intertwined ambiguities: Meat, in vitro meat, and the ideological construction of the marketplace. Journal of Consumer Behavior 12 (6): 472-482.

Circus, V.E., and R. Robison. 2019. Exploring perceptions of sustainable proteins and meat attachment. British Food Journal 121 (2): 533-545.

Clark, L.F., and A.-M. Bogdan. 2019. The role of plant-based foods in Canadian diets: A survey examining food choices, motivations and dietary identity. Journal of Food Products Marketing 25 (4): 355-377.

Cole, M., and K. Morgan. 2013. Engineering freedom? A critique of biotechnological routes to animal liberation. Configurations 21 (2): 201-229.

de Boer, J., and H. Aiking. 2018. Prospects for pro-environmental protein consumption in Europe: Cultural, culinary, economic and psychological factors. Appetite 121: 29-40.

de Boer, J., and H. Aiking. 2019. Strategies towards healthy and sustainable protein consumption: A transition framework at the levels of diets, dishes, and dish ingredients. Food Quality and Preference 73: 171-181.

Dilworth, T., and A. McGregor. 2015. Moral steaks? Ethical discourses of in vitro meat in academia and australia. Journal of Agricultural and Environmental Ethics 28: 85-107. 
Egolf, A., C. Hartmann, and M. Siegrist. 2019. When evolution works against the future: Disgust's contributions to the acceptance of new food technologies. Risk Analysis 39 (7): 1546-1559.

Elzerman, J.E., P.A. Luning, and M.A.J.S. van Boekel. 2013. Exploring meat substitutes: Consumer experiences and contextual factors. British Food Journal 115 (5): 700-710.

Farrell, E.L., K.M. Doma, E.R. Leith-Bailey, V.D. Soucier, and A.M. Duncan. 2019. Health claims and information sources in relation to bean consumption in older adults. Appetite 140: 318-327.

Ferrari, A., and A. Lösch. 2017. How smart grid meets in vitro meat: On visions as socio-epistemic practices. Nanoethics 11: 75-91.

Figueira, N., F. Curtain, E. Beck, and S. Grafenauer. 2019. Consumer understanding and culinary use of legumes in Australia. Nutrients 11 (7): 1575.

Fuentes, C., and M. Fuentes. 2017. Making a market for alternatives: Marketing devices and the qualification of a vegan milk substitute. Journal of Marketing Management 33 (7-8): 529-555.

Galusky, W. 2014. Technology as responsibility: Failure, food animals, and lab-grown meat. Journal of Agricultural and Environmental Ethics 27: 931-948.

Geels, F.W. 2004. From sectoral systems of innovation to socio-technical systems: Insights about dynamics and change from sociology and institutional theory. Research Policy 33 (6-7): 897-920.

Goodman, M.K. 2016. Food geographies I: Relational foodscapes and the busy-ness of being more-than-food. Progress in Human Geography 40 (2): 257-266.

Goodwin, J.N., and C.W. Shoulders. 2013. The future of meat: A qualitative analysis of cultured meat media coverage. Meat Science 95 (3): 445-450.

Graça, J., C.A. Godinho, and M. Truninger. 2019. Reducing meat consumption and following plant-based diets: Current evidence and future directions to inform integrated transitions. Trends in Food Science \& Technology 91: 380-390.

Haas, R., A. Schnepps, A. Pichler, and O. Meixner. 2019. Cow milk versus plant-based milk substitutes: A comparison of product image and motivational structure of consumption. Sustainability 11 (18): 5046.

Hartmann, C., and M. Siegrist. 2017. Consumer perception and behaviour regarding sustainable protein consumption: A systematic review. Trends in Food Science \& Technology 61: $11-25$.

Havemeier, S., J. Erickson, and J. Slavin. 2017. Dietary guidance for pulses: The challenge and opportunity to be part of both the vegetable and protein food groups. Annals of the New York Academy of Sciences 1392 (1): 58-66.

Hayes-Conroy, J., and A. Hayes-Conroy. 2010. Visceral Geographies: Mattering, Relating, and Defying. Geography Compass 4 (9): 1273-1283.

Hayes-Conroy, J., and A. Hayes-Conroy. 2013. Veggies and visceralities: A political ecology of food and feeling. Emotion, Space and Society 6: 81-90.

Hocquette, J.-F. 2016. Is in vitro meat the solution for the future? Meat Science 120: 167-176.

Hoek, A.C., P.A. Luning, P. Weijzen, W. Engels, F.J. Kok, and C. de Graaf. 2011. Replacement of meat by meat substitutes. A survey on person- and product-related factors in consumer acceptance. Appetite 56 (3): 662-673.

House, J. 2019. Insects are not 'the new sushi': Theories of practice and the acceptance of novel foods. Social \& Cultural Geography 20 (9): 1285-1306.

Huan-Niemi, E., M. Kaljonen, M. Knuuttila, J. Niemi, and M. Saarinen. 2020. The impacts of dietary change in Finland: Food system approach. Agriculture and Food Science 29 (4): 372-384.
Jallinoja, P., M. Niva, and T. Latvala. 2016. Future of sustainable eating? Examining the potential for expanding bean eating in a meat-eating culture. Futures, SI: Futures for Food 83: 4-14.

Jönsson, E. 2016. Benevolent technotopias and hitherto unimaginable meats: Tracing the promises of in vitro meat. Social Studies of Science 46 (5): 725-748.

Jönsson, E., T. Linné, and A. McCrow-Young. 2019. Many meats and many milks? The ontological politics of a proposed post-animal revolution. Science as Culture 28 (1): 70-97.

Kadim, I.T., O. Mahgoub, S. Baqir, B. Faye, and R. Purchas. 2015. Cultured meat from muscle stem cells: A review of challenges and prospects. Journal of Integrative Agriculture 14 (2): 222-233.

Kahneman, D. 2011. Thinking fast and slow. London: Penguin.

Kaljonen, M., M. Salo, J. Lyytimäki, and E. Furman. 2020. From isolated labels and nudges to sustained tinkering: Assessing longterm changes in sustainable eating at a lunch restaurant. British Food Journal 122 (11): 3313-3329.

Keefe, L.M. 2018. \#FakeMeat: How big a deal will animal meat analogs ultimately be? Animal Frontiers 8 (3): 30-37.

Kramer, C. 2015. A name. In What is in vitro meat?, ed. N. Stephens, C. Karmer, Z. Denfeld, and R. Strand, 33-35. London: The Centre for Genomic Gastronomy, Ditto Press.

Laestadius, L.I. 2015. Public perceptions of the ethics of in-vitro meat: Determining an appropriate course of action. Journal of Agricultural and Environmental Ethics 28: 991-1009.

Ledin, P., and D. Machin. 2019. Replacing actual political activism with ethical shopping: The case of Oatly. Discourse, Context \& Media 34: 100344.

Lee, A. 2018. Meat-ing demand: Is in vitro meat a pragmatic, problematic, or paradoxical solution? Canadian Journal of Women and the Law 30 (1): 1-14.

Liberati, A., D.G. Altman, J. Tetzlaff, C. Mulrow, P.C. Gøtzsche, J.P.A. Ioannidis, M. Clarke, P.J. Devereaux, J. Kleijnen, and D. Moher. 2009. The PRISMA statement for reporting systematic reviews and meta-analyses of studies that evaluate health care interventions: explanation and elaboration. Journal of Clinical Epidemiology 62 (10): e1-e34.

Lupton, D., and B. Turner. 2018. Food of the future? Consumer responses to the idea of 3D-printed meat and insect-based foods. Food and Foodways 26 (4): 269-289.

Majima, S. 2014. A brief thought on the future of global ethics: Military robots and new food technologies. Journal of Global Ethics 10 (1): 53-55.

Malek, L., W.J. Umberger, and E. Goddard. 2019. Committed vs. uncommitted meat eaters: Understanding willingness to change protein consumption. Appetite 138: 115-126.

Mason, P.J., and T. Lang. 2017. Sustainable diets: How ecological nutrition can transform consumption and the food system. London: Routledge.

McBey, D., D. Watts, and A.M. Johnstone. 2019. Nudging, formulating new products, and the lifecourse: A qualitative assessment of the viability of three methods for reducing Scottish meat consumption for health, ethical, and environmental reasons. Appetite 142: 104349.

McGregor, A., and D. Houston. 2018. Cattle in the Anthropocene: Four propositions. Transactions of the Institute of British Geographers 43 (1): 3-16.

Metcalf, J. 2013. Meet Shmeat: Food system ethics, biotechnology and re-worlding technoscience. Parallax 19 (1): 74-87.

Milburn, J. 2016. Chewing over in vitro meat: Animal ethics, cannibalism and social progress. Res Publica 22: 249-265.

Milburn, J. 2018. Death-free dairy? The ethics of clean milk. Journal of Agricultural and Environmental Ethics 31: 261-279.

Mol, A. 1999. Ontological politics: A word and some questions. The Sociological Review 47: 74-89. 
Moon, W., S.K. Balasubramanian, and A. Rimal. 2011. Health claims and consumers' behavioral intentions: The case of soy-based food. Food Policy 36 (4): 480-489.

Morris, C., J. Mylan, and E. Beech. 2019. Substitution and food system de-animalisation. International Journal of Sociology of Agriculture \& Food 25 (1): 42-58.

Mouat, M.J., and R. Prince. 2018. Cultured meat and cowless milk: On making markets for animal-free food. Journal of Cultural Economy 11 (4): 315-329.

Murray, A. 2018. Meat cultures: Lab-grown meat and the politics of contamination. BioSocieties 13: 513-534.

Mylan, J., C. Morris, E. Beech, and F.W. Geels. 2019. Rage against the regime: Niche-regime interactions in the societal embedding of plant-based milk. Environmental Innovation and Societal Transitions 31: 233-247.

O'Riordan, K., A. Fotopoulou, and N. Stephens. 2017. The first bite: Imaginaries, promotional publics and the laboratory grown burger. Public Understanding of Science 26 (2): 48-163.

Palmer, S.M., D.M. Winham, A.M. Oberhauser, and R.E. Litchfield. 2018. Socio-ecological barriers to dry grain pulse consumption among low-income women: A mixed methods approach. Nutrients 10 (8): 1108.

Pel, B. 2016. Trojan horses in transitions: A dialectical perspective on innovation 'capture.' Journal of Environmental Policy \& Planning 18 (5): 673-691.

Peltola, T., M. Kaljonen, and M. Kettunen. 2020. Embodied public experiments on sustainable eating: demonstrating alternative proteins in Finnish schools. Sustainability: Science, Practice and Policy 16 (1): 184-196.

Petetin, L. 2014. Frankenburgers, risks and approval. European Journal of Risk Regulation 5: 168-186.

Plessz, M., and S. Wahlen. 2020. All practices are shared, but some more than others: Sharedness of social practices and time-use in food consumption. Journal of Consumer Culture. https://doi. org/10.1177/1469540520907146.

Pluhar, E.B. 2010. Meat and morality: Alternatives to factory farming. Journal of Agricultural and Environmental Ethics 23: 455-468.

Rettie, R., K. Burchell, and D. Riley. 2012. Normalising green behaviours: A new approach to sustainability marketing. Journal of Marketing Management 28 (3-4): 420-444.

Sachs, A., and S. Kettenmann. 2019. A burger by any other name: regulatory challenges and opportunities for cell-cultured meat. Scitech Lawyer 15 (2): 18-23.

Schaefer, G.O., and J. Savulescu. 2014. The ethics of producing in vitro meat. Journal of Applied Philosophy 31 (2): 188-202.

Schösler, H., J. de Boer, and J.J. Boersema. 2012. Can we cut out the meat of the dish? Constructing consumer-oriented pathways towards meat substitution. Appetite 58 (1): 39-47.

Sexton, A. 2016. Alternative proteins and the (non)stuff of "meat." Gastronomica: The Journal of Critical Food Studies 16 (3): 66-78.

Sexton, A. 2018. Eating for the post-Anthropocene: Alternative proteins and the biopolitics of edibility. Transactions of the Institute of British Geographers 43 (4): 586-600.

Sexton, A.E., T. Garnett, and J. Lorimer. 2019. Framing the future of food: The contested promises of alternative proteins. Environment and Planning E: Nature and Space 2 (1): 47-72.

Shaw, E., and M.M.C. Iomaire. 2019. A comparative analysis of the attitudes of rural and urban consumers towards cultured meat. British Food Journal 121 (8): 1782-1800.

Siegrist, M., and B. Sütterlin. 2017. Importance of perceived naturalness for acceptance of food additives and cultured meat. Appetite 113: 320-326.

Siegrist, M., B. Sütterlin, and C. Hartmann. 2018. Perceived naturalness and evoked disgust influence acceptance of cultured meat. Meat Science 139: 213-219.
Smith, A., and R. Raven. 2012. What is protective space? Reconsidering niches in transitions to sustainability. Research Policy 41 (6): $1025-1036$

Snyder, H. 2019. Literature review as a research methodology: An overview and guidelines. Journal of Business Research 104: 333-339.

Stephens, N. 2013. Growing meat in laboratories: The promise, ontology, and ethical boundary-work of using muscle cells to make food. Configurations 21 (2): 159-181.

Stephens, N., L. Di Silvio, I. Dunsford, M. Ellis, A. Glencross, and A. Sexton. 2018a. Bringing cultured meat to market: Technical, sociopolitical, and regulatory challenges in cellular agriculture. Trends in Food Science \& Technology 78: 155-166.

Stephens, N., E. King, and C. Lyall. 2018b. Blood, meat, and upscaling tissue engineering: Promises, anticipated markets, and performativity in the biomedical and agri-food sectors. BioSocieties 13: 368-388.

Stephens, N., and M. Ruivenkamp. 2016. Promise and ontological ambiguity in the in vitro meat imagescape: From laboratory myotubes to the cultured burger. Science as Culture 25 (3): 327-355.

Tai, S. 2020. Legalizing the meaning of meat. Loyola University Chicago Law Journal 51 (3): 743-789.

Thaler, R.H., and C.R. Sunstein. 2008. Nudge: Improving decisions about health, wealth, and happiness. Yale: Yale University Press.

Torraco, R.J. 2016. Writing integrative literature reviews: Using the past and present to explore the future. Human Resource Development Review 15 (4): 404-428.

Tu, V.P., F. Husson, A. Sutan, D.T. Ha, and D. Valentin. 2012. For me the taste of soy is not a barrier to its consumption. And how about you? Appetite 58 (3): 914-921.

Tucker, C.A. 2014. The significance of sensory appeal for reduced meat consumption. Appetite 81: 168-179.

Tuomisto, H., and J. Teixeira de Mattos. 2011. Environmental impacts of cultured meat production. Environmental Science \& Technology 45 (14): 6117-6123.

Tziva, M., S.O. Negro, A. Kalfagianni, and M.P. Hekkert. 2020. Understanding the protein transition: The rise of plant-based meat substitutes. Environmental Innovation and Societal Transitions 35: 217-231.

Vainio, A., X. Irz, and H. Hartikainen. 2018. How effective are messages and their characteristics in changing behavioural intentions to substitute plant-based foods for red meat? The mediating role of prior beliefs. Appetite 125: 217-224.

Vainio, A., M. Niva, P. Jallinoja, and T. Latvala. 2016. From beef to beans: Eating motives and the replacement of animal proteins with plant proteins among Finnish consumers. Appetite 106: 92-100.

van der Valk, J., K. Bieback, C. Buta, B. Cochrane, W. Dirks, J. Fu, J. Hickman, C. Hohensee, R. Kolar, M. Liebsch, F. Pistollato, M. Schulz, D. Thieme, T. Weber, J. Wiest, S. Winkler, and G. Gstraunthaler. 2018. Fetal bovine serum (FBS): Past-present-future. ALTEX-Alternatives to Animal Experimentation 35 (1): 99-118.

van der Weele, C., and C. Driessen. 2013. Emerging profiles for cultured meat; Ethics through and as Design. Animals 3 (3): 647-662.

van der Weele, C., P. Feindt, A.J. van der Goot, B. van Mierlo, and M. van Boekel. 2019. Meat alternatives: An integrative comparison. Trends in Food Science and Technology 88: 505-512.

Verbeke, W., A. Marcu, P. Rutsaert, R. Gaspar, B. Seibt, D. Fletcher, and J. Barnett. 2015a. "Would you eat cultured meat?": Consumers' reactions and attitude formation in Belgium, Portugal and the United Kingdom. Meat Science 102: 49-58.

Verbeke, W., P. Sans, and E.J. Van Loo. 2015b. Challenges and prospects for consumer acceptance of cultured meat. Journal of Integrative Agriculture 14 (2): 285-294.

Wansink, B., M. Shimizu, and A. Brumberg. 2014. Dispelling myths about a new healthful food can be more motivating than promoting nutritional benefits: The case of Tofu. Eating Behaviors 15 (2): $318-320$ 
Warde, A. 2016. Practice of eating. Cambridge: Polity Press.

Weinrich, R. 2018. Cross-cultural comparison between German, French and Dutch consumer preferences for meat substitutes. Sustainability 10 (6): 1819.

Weinrich, R. 2019. Opportunities for the adoption of health-based sustainable dietary patterns: A review on consumer research of meat substitutes. Sustainability 11 (15): 1-15.

Wilks, M., and C.J.C. Phillips. 2017. Attitudes to in vitro meat: A survey of potential consumers in the United States. PLoS ONE 12 (2): e0171904.

Wilks, M., C.J.C. Phillips, K. Fielding, and M.J. Hornsey. 2019. Testing potential psychological predictors of attitudes towards cultured meat. Appetite 136: 137-145.
Publisher's Note Springer Nature remains neutral with regard to jurisdictional claims in published maps and institutional affiliations.

Annika Lonkila is a Researcher at the Finnish Environment Institute (SYKE) and a PhD student at the Department of Geographical and Historical Studies at University of Eastern Finland. Her research focuses on sustainable food systems.

Minna Kaljonen acts as a Research Professor at the Finnish Environment Institute (SYKE). Her research has focused on environmental governance and sustainable food system transitions. She currently leads a transdisciplinary research project on just food system transition. 